\title{
Disease Severity, Clinical Characteristics and Outcome of Patients Hospitalized with Novel Coronavirus Disease at a Tertiary Care Hospital, Rawalpindi
}

\author{
Muhammad Mahtab Shabir ${ }^{1 *}$, Shazia Nisar ${ }^{1}$, Zobia Urooj ${ }^{2}$, Uzma Qayyum ${ }^{1}$, Fozia Fatima ${ }^{3}$, Zahid Hussain ${ }^{3}$
}

\section{ABSTRACT}

Objective: To describe the clinical characteristics, signs \& symptoms, disease severity, and outcome of patients admitted with novel coronavirus infection.

Study Design: Comparative cross-sectional study.

Place and Duration of Study: The study was conducted in the Department of Medicine of Pak-Emirates Military Hospital, (PEMH), Rawalpindi from May $1^{\text {st }}, 2020$ to June $30^{\text {th }}, 2020$.

Materials and Methods: Patients hospitalized with novel corona virus infection during the study period were prospectively enrolled in this study. Patients at least 15 years and above, either gender, hospitalized with confirmed diagnosis of covid-19 (SARS-CoV-2) were eligible to be enrolled. The study outcomes included disease presentation, severity at time of reporting, admission to critical care or intensive care unit and mortality. Patients were identified as mild, moderate, severe and critical in accordance with World Health Organization guidelines, based on symptom severity, laboratory and imaging findings.

Results: There were 400 hospitalized patients with confirmed SARS-CoV-2, out of which 51 (12.8\%) were females, while 349 (87.3\%) were males with overall mean age of $48.45 \pm 16.2$ years. There were $300(75.0 \%)$ patients with mild disease severity, while 65 (16.3\%), 20 (5.0\%) and 15 (3.8\%) with moderate, severe and critical disease condition, respectively. The number of patients died were 22, with fatality rate of 5.5\%. Age and presence of comorbidities (cardiac disease, diabetes, hypertension, pulmonary disease, kidney disease) were significantly associated with disease severity and death due to novel coronavirus infection.

Conclusion: Patients with older age, diabetes, hypertension, pulmonary disease, kidney disease were at higher risk of developing severe disease condition and death due to novel coronavirus infection.

\section{Key Words: Covid-19, Hospitalized Patients, Novel Coronavirus Disease, SARS-CoV-2, Signs and Symptoms.}

How to cite this: Shabir MM, Nisar S, Urooj Z, Qayyum U, Fatima F, Hussain Z. Disease Severity, Clinical Characteristics and Outcome of Patients Hospitalized with Novel Coronavirus Disease at a Tertiary Care Hospital, Rawalpindi. Life and Science. 2021; 2(4): 145-150. doi: http://doi.org/10.37185/LnS.1.1.180

This is an Open Access article distributed under the terms of the Creative Commons Attribution License (http://creativecommons.org/licenses/by/4.0), which permits unrestricted use, distribution, and reproduction in any medium, provided the original work is properly cited.

\section{Introduction}

In December 2019, a novel virus originated from Wuhan city of China, known as Severe Acute Respiratory Syndrome Coronavirus (SARS CoV 2). Novel coronavirus belongs to the same family of

${ }^{1}$ Department of Medicine/Infectious Diseases

${ }^{2}$ Department of /Anesthesia/ITC

${ }^{3}$ Department of Medicine/ Rheumatology

Pak-Emirates Military Hospital, (PEMH), Rawalpindi

Correspondence:

Dr. Muhammad Mahtab Shabir

Department of Medicine/Infectious Diseases

Pak-Emirates Military Hospital, (PEMH), Rawalpindi

E-mail:drmehtabshabbir@gmail.com

Funding Source: NIL; Conflict of Interest: NIL

Received: Dec 28, 2020; Revised: Mar 09, 2021

Accepted: Mar 09, 2021

145 viruses as MERS and SARS coronaviruses. ${ }^{1}$ The novel coronavirus outbreak widely spread to a large number of countries within short span of time. World Health Organization on $11^{\text {th }}$ March 2020 declaredthis disease a pandemicwhich infected 215 countries and territories around the world with around 43.8 million confirmed cases and 1.2 million deaths. ${ }^{2}$

Novel corona virus causes severe acute respiratory distress among infected patients, with a quite variable case presentation and symptom severity. With an incubation period of 1 - 14 days, most commonly ranging from $3-7$ days, the disease has been divided into three clinical stages of infection on the basis of disease severity. ${ }^{3}$ The early infection 
response phase (stage 1 ), is asymptomatic or mild in naturewhere infection is limited to upper respiratory tract; themoderate pulmonary phase (stage 2) involves lower respiratory tract infection leading to development of pneumonia; and severe hyper inflammatory phase (stage 3 ) results in development of a cytokine storm syndrome, acute pulmonary injury, sepsis, multiple-organ failure and death. ${ }^{4}$

In patients with mild to moderate symptoms, fever, sore throat, cough, nasal congestion and fatigue are the most common presenting complaints. Some of the patients also present with gastrointestinal disturbances including nausea, vomiting, diarrhea and cramps, and more severe patients experience breathing difficulty, tachypnea, in-drawing of chest and pneumonia. ${ }^{5}$ Old age, weak immune system and underlying comorbidities e.g. diabetes, hypertension, cardiovascular and cerebrovascular diseases, are the significant risk factors associated with progressive severity of illness. ${ }^{6}$ The case fatality ratio for this illness is also very wide, which lies between $0.1 \%-25.0 \% .{ }^{4,7}$ The true value is difficult to estimate at this point in time because actual level of transmission of infection is underestimated in many countries because substantial portion of people infected with the virus never reported to the healthcare setup due to mild to moderate symptoms.

There had been no approved treatment options to prevent or treat this novel infection so far, thus most of the times the focus has been on symptomatic treatment and supportive measures. ${ }^{8}$ Treatment modalities being used to treat novel coronavirus patients are based on experiences from previous viral outbreaks including MERS, SARS, Ebola etc. Most commonly used treatment options include antiviral drugs, corticosteroids, antimicrobial therapy, anticoagulants, oxygen therapy, continuous renal replacement therapy, convalescent plasma therapy, and monoclonal antibodies etc. ${ }^{9}$

In this study we aim to describe the epidemiological data, clinical characteristics, signs andsymptoms, disease severity, and outcome of patients admitted with novel coronavirus infection in a tertiary care hospital of Rawalpindi.

\section{Materials and Methods}

This prospective cohort was conducted from May $1^{\text {st }}$, 2020 to June $30^{\text {th }}, 2020$. The study was approved from Institutional Review Board for ethical clearance (IRB letter number A/28/EC/212/2020). All consecutive patients hospitalized with novel corona virus infection during the study period were prospectively enrolled in this study. Patients at least 15 years or above, either gender, hospitalized with confirmed diagnosis of covid-19 (SARS-CoV-2) were eligible to be enrolled. Case diagnosis was made in accordance with standardized criteria, nasal and pharyngeal swabs samples tested positive for presence of SARS-CoV-2 virus via real-time reverse polymerase chain reaction(PCR) test were labelled as confirmed cases.

"Novel coronavirus (nCoV) acute respiratory infection clinical characterization data tool" (version 9.2) ${ }^{10}$ developed by International Severe Acute Respiratory and emerging Infections Consortium (ISARIC) and World Health Organization (WHO) was used to collect data for this study. The case report form was filled for all the patients at the time of admission, on ICU admission and daily up to discharge or death. Baseline data including demographics and clinical characteristics, onset \& details of symptoms and admission details were recorded on the first day of admission. Pathogen detection results and other laboratory findings were recorded whenever requested, and patient management details including daily assessments, medications, complications were recorded on daily basis. The survival data was noted at discharge/death.

The study outcomes included disease presentation, disease severity at admission, admission to critical care or intensive care unit and mortality at follow up. Patients were identified as mild, moderate, severe and critical in accordance with World Health Organization guidelines, based on symptom severity, laboratory and imaging findings. ${ }^{11}$ Patients with fever, slight upper respiratory symptoms and negative finding of pneumonia on imaging were labelled to have mild disease condition. Patients with shortness of breath, mild pneumonia with no need of oxygen therapy were defined to have moderate disease condition. Patients with severe respiratory distress, difficulty in breathing, respiratory rate of more than 30 breaths per minute, oxygen saturation of less than $93 \%$ on room air were said to have severe disease. Whereas those with 
worsening respiratory symptoms, bilateral opacities on imaging, respiratory failure, acute respiratory distress syndrome requiring mechanical ventilation, defined by Berlin definition,organ failure, shock, requiring ICU admission were defined to have critical disease condition. ${ }^{12,13}$ Patients with decrease in fever, relief in respiratory symptoms, disappearance of pulmonary opacity on imaging, and a negative realtime PCR for detection of SARS-CoV-2 were considered to be showing improvement with time. The data was shifted from WHO case report forms to data management software (IBM SPSS version 23.0). Descriptive statistics for continuous variables were reported as mean and standard deviation, while for categorical data frequency and percentages were used. Inferential statistics including categorical group comparisons were made by using chi-square test, while for mean comparison among different groups' independent samples T-test and one-way ANOVA was used. A value of $p$ less than or equal to 0.05 was considered significant in this study. Univariate and multivariate analysis was done using logistic regression analysis and the associations were expressed as odds ratio and $95 \%$ confidence interval.

\section{Results}

There were 400 hospitalized patients with confirmed SARS-CoV-2 diagnosis prospectively enrolled in the study and followed up till death/discharge from hospital. There were 51 (12.8\%) females, out of which 2 (3.9\%) were pregnant, while 349 (87.3\%) males with overall mean age of $48.45 \pm 16.2$ years (age range $19-75$ ).Gender specific mean age was found to be $47.47 \pm 16.2$ years and $48.59 \pm 16.3$ years for females and males respectively with no significant difference. History of travel was reported by 50 (12.5\%), while 361 (90.3\%) reported history of close contact with confirmed case within past one week. Out of 400,41 (10.3\%) patients were healthcare workers, 11 (2.8\%) were laboratory workers while remaining $347(86.7 \%)$ were from general population. Baseline characteristics of patients including comorbities, are shown in table 1.

Majority of the patients [394 (98.5\%)] presented with fever, 382 (95.5\%) cough, 384 (96.0\%) sore throat, while 16 (4.0\%) had runny nose, 24 (6.0\%) experienced loss of smell/taste, and $3(0.8 \%)$ had ear pain. Fatigue was also one of the most common symptoms, reported by 380 (95.0\%) of the patients.
Around 15 (3.8\%) patients presented with wheezing, in addition to other common signs/symptoms, 10 (2.5\%) had vomiting, 17 (4.3\%) had diarrhea, 32 (8.0\%) had headache, conjunctivitis was noted in 2 (0.5\%) patients, $6(1.5 \%)$ had skin rash, 13 (3.3\%) reported to have chest pain, while $57(14.2 \%)$ and 11 $(2.8 \%)$ had muscle and joint pain. More serious symptoms comprised of shortness of breath in 17 (4.3\%) patients, indrawing of lower chest wall in 4 (1.0\%) patients, altered consciousness in $4(1.0 \%)$ patients and seizure in $1(0.3 \%)$ patient was observed.

\begin{tabular}{|c|c|c|}
\hline Characteristics & $\begin{array}{l}\text { Frequencies } \\
\text { (n) }\end{array}$ & $\begin{array}{c}\text { Percentages } \\
\text { (\%) }\end{array}$ \\
\hline \multicolumn{3}{|l|}{ Epidemiological Data } \\
\hline Age $($ mean $\pm S D)$ & \multicolumn{2}{|c|}{$48.45 \pm 16.2$ years } \\
\hline \multicolumn{3}{|l|}{ Gender } \\
\hline - Females & 51 & $12.8 \%$ \\
\hline - Males & 349 & $87.3 \%$ \\
\hline History of travel & 50 & $12.5 \%$ \\
\hline $\begin{array}{l}\text { Direct contact with confirmed } \\
\text { covid-19 patient } \\
\text { Status }\end{array}$ & 361 & $90.3 \%$ \\
\hline - Healthcare worker & 41 & $10.3 \%$ \\
\hline - Laboratory worker & 11 & $2.8 \%$ \\
\hline - General population & 347 & $86.7 \%$ \\
\hline \multicolumn{2}{|l|}{ Clinical Data } & \\
\hline - Cardiac disease & 19 & $4.8 \%$ \\
\hline - Pulmonary & 18 & $4.5 \%$ \\
\hline disease/COPD & 9 & $2.3 \%$ \\
\hline - Asthma & 24 & $6.0 \%$ \\
\hline - Kidney disease & 5 & $1.3 \%$ \\
\hline - Liver disease & 21 & $5.3 \%$ \\
\hline - Diabetes & 17 & $4.3 \%$ \\
\hline - Hypertension & 4 & $1.06 \%$ \\
\hline - Rheumatic arthritis & & \\
\hline Current smokers & 33 & $8.3 \%$ \\
\hline Obesity (BMI>25) & 22 & $5.5 \%$ \\
\hline
\end{tabular}

On the basis of presenting symptoms, and worsening of symptoms after hospital admission, the study patients were divided into four categories of disease severity. There were 300 (75.0\%) patients who had mild disease severity, $65(16.3 \%)$ patients had moderate disease severity, 20 (5.0\%) were identified to had severe disease and $15(3.8 \%)$ patients were critical who required admission to the ICU and mechanical ventilation as depicted in figure 1.

Oxygen therapy was administered to 23 (5.8\%) of the patients belonging to severe/critical group, while 10 $(2.5 \%)$ and $5(1.3 \%)$ required non-invasive and invasive mechanical ventilation respectively. 


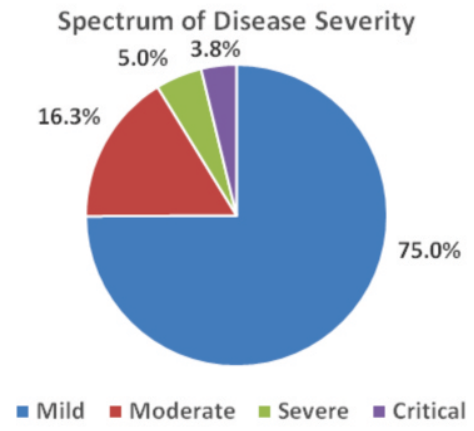

Fig 1: Distribution of disease severity spectrum among patients admitted with novel coronavirus disease

Vasopressor inotropic support was required by 14 (3.5\%) patients, while intravenous steroids, antibiotics and antiviral drugs were administered to $38(9.5 \%)$ severe/critically ill patients.

Out of 400, 22 (5.5\%) patients died while 378 (94.5\%) survived and were discharged after negative SARSCoV-2 real-time PCR test. Mean hospital stay in days was compared with disease severity using one-way ANOVA test. The hospital stay was significantly highest for critical patients, followed by severe, moderate and mild disease condition (18.5 \pm 4.0 vs $17.13 \pm 4.2$ vs14.6 \pm 1.5 vs $14.03 \pm 2.5$ respectively, $p<0.001)$. Chi-square test was used to compare disease severity with mortality outcome. It was found that disease severity was significantly associated with mortality, as most of the patients with critical disease died [12/15 (80.0\%)] as compared to patients with severe and moderate disease [8/12 (40.0\%) and 2/63 (3.1\%) respectively]. Comparison of age was done with disease severity using one-way ANOVA, and independent samples Ttest was used to compare age with mortality outcome. Similarly, comparison of comorbidities with disease severity and mortality outcome was done by using Chi-square test. Patients who died due to coronavirus infection were significantly older as compared to those whose symptoms improved and were discharged (55.64 \pm 15.1 vs 48.03 \pm 16.2 , $p=0.033$ ) as given in table 2 .

Patients who developed severe and critical disease severity were of older age as compared to those with mild or moderate disease i.e. 46.96 \pm 16.1 vs $52.34 \pm 16.1$ vs $53.80 \pm 16.5$ vs $54.27 \pm 14.3$ years ( $p=0.015)$ for mild, moderate, severe and critical disease condition respectively. Upon multivariate analysis it was found that patients with pulmonary

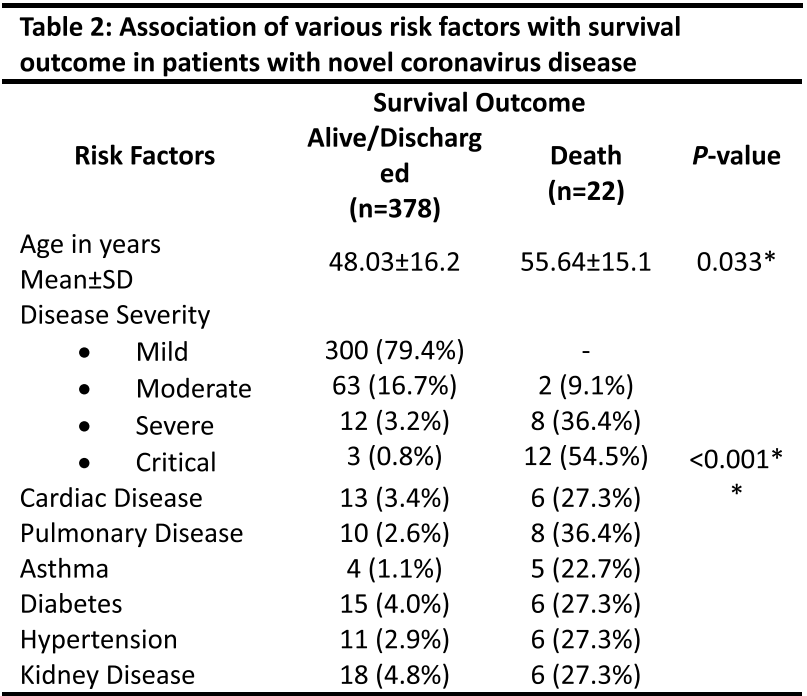

*Independent-samples T-test, ${ }^{* *}$ Chi-square test

disease were 28.5 times more likely to die due to novel corona virus infection as compared to others (OR=28.5, 95\% Cl $7.8-104.5, p<0.001)$, similarly odds of death due to coronavirus infection for patients with asthma and kidney disease increased $27.9(95 \% \mathrm{Cl} 5.1-153.9, p<0.001)$ and 6.5 folds $(95 \%$ $\mathrm{Cl} 1.5-27.2, p=0.01$ ) as shown in table 3 .

\begin{tabular}{lccc}
\hline $\begin{array}{l}\text { Table 3: Multivariate analysis showing significant predictor } \\
\text { variables of mortality among confirmed novel coronavirus } \\
\text { patients }\end{array}$ & \multicolumn{4}{l}{} \\
\hline $\begin{array}{l}\text { Predictor } \\
\text { factors }\end{array}$ & Odds & $\begin{array}{c}\text { 95\% Confidence } \\
\text { Interval }\end{array}$ & $p$-value \\
Asthma & 27.9 & $5.1-153.9$ & $<0.001$ \\
$\begin{array}{l}\text { Pulmonary } \\
\text { disease }\end{array}$ & 28.5 & $7.8-104.5$ & $<0.001$ \\
Kidney disease & 6.5 & $1.5-27.2$ & 0.01 \\
\hline
\end{tabular}

\section{Discussion}

The findings from our study are in line with results reported in many other studies highlighting the disease severity pattern and mortality ratio. Li LQ et al ${ }^{14}$ reported similar fatality rate of $5 \%$ in a study of 1994 covid-19 patients extracted from 10 different studies. Zhang et al $^{15}$ reported an overall mortality rate as $3.7 \%$.

Fever was the most commonly reported sign/symptom for novel coronavirus patients, followed by cough, sore throat and fatigue. These finding are consistent with results from other studies including Wang R et al, ${ }^{16} \mathrm{Xu} X \mathrm{XW}$ et al, ${ }^{17}$ and Sun $\mathrm{Y}$ et $\mathrm{al}^{18}$, Guan $Z$ et $\mathrm{al}^{19}$ reported a similar prevalence of respiratory and gastrointestinal symptoms observed in 1099 patients of covid-19. Pan Li et al ${ }^{20}$ reported a 
higher rate of symptoms related to gastrointestinal tract including vomiting and diarrhea where around $50 \%$ of the patients showed these signs, where as in our study only $12 \%$ of the patients manifested gastrointestinal symptoms. Serious respiratory symptoms including opacities on imaging scan, shortness of breath, unconsciousness and wheezing are rarely encountered signs/symptoms of coronavirus infection but are significantly associated with disease severity and death as reported by Rothan SA et al $^{21}$ and Jin $Y$ et al. ${ }^{1}$ Similar results were observed in current study where serious respiratory symptoms were significantly associated with poor outcome and disease severity.

Age was found to be significantly associated with mortality and disease severity in this study. Patients who died of coronavirus infection were significantly older as compared to others $(55.64 \pm 15.1$ vs $48.03 \pm 16.2$ years, $p=0.033$ ). Patients who developed severe and critical disease severity were of older age as compared to those with mild or moderate disease. Similar results were reported by Lian $\mathrm{J}$ et $\mathrm{al}^{22}$ and Zhang J et $\mathrm{al}^{15}$ that patients with older age were more prone to develop severe covid-19 symptoms and were also associated with poor outcome i.e. chances of death were more in older patients. The most likely explanation for this phenomenon was published by Zhou $\mathrm{F}$ et $\mathrm{al}^{23}$ who concluded that old age is linked to declined cell-mediated immune function and decreased humoral immune function which results in poor viral replication control.

Presence of comorbidities including cardiac disease, pulmonary disease, asthma, kidney disease, diabetes and hypertension are reported to be significantly associated with development of severe disease condition and such patients are more likely to die due to novel coronavirus infection. ${ }^{24,25}$ Metaanalysis conducted by Yang $\mathrm{J}$ et $\mathrm{al}^{22}$ reported a pooled odds ratio of $2.36(95 \% \mathrm{Cl} 1.46-3.82$, $p<0.001), 2.46(95 \% \mathrm{Cl} 1.76-3.44, p<0.001)$ and 3.42 $(95 \% \mathrm{Cl} 1.88-6.22, p=0.001)$ associated withhypertension, pulmonary and cardiac disease respectively for patients to develop severe disease condition. In our study cardiac disease was not found to be significantly associated with severe disease condition or death which is contrary to meta-analysis performed by Yang J et al. ${ }^{24}$ Similarly, Emami A et al ${ }^{25}$ in another meta-analysis reported pooled prevalence of $16.37 \%(95 \% \mathrm{Cl} 10.15 \%-23.65 \%$, $p<0.001), 12.11 \%(95 \% \mathrm{Cl} 4.40 \%-22.75 \%, p=0.001)$, $7.63 \%(95 \% \mathrm{Cl} 3.83 \%-12.43 \%, p<0.001)$ and $7.87 \%$ (95\% Cl 6.5\% - 9.28\%, $p=0.001)$ for hypertension, cardiovascular disease, smoking and diabetes in patients severely infected with novel coronavirus infection. The results are quite similar to present study results where most of these comorbidities were found to be potential risk factors of severe novel coronavirus disease and death.

\section{Conclusion}

Patients with older age, diabetes, hypertension, pulmonary disease, kidney disease are at higher risk of developing severe disease condition and death due to novel coronavirus infection. It is recommended that patients with existing comorbidities should be managed proactively for covid-19 infection, keeping in mind their high-risk to develop associated complications.

\section{REFERENCE}

1. Jin Y, Yang H, Ji W, Wu W, Chen S, Zhang W, et al. Virology, epidemiology, pathogenesis, and control of COVID-19. Viruses. 2020; 12: 372-6.

2. Worldo'meter. Countries where COVID-19 has spread. [Updated on 27th October 2020, Accessed 27th October 2020]. [Available at: https://www.worldometers.info /coronavirus/countries-where-coronavirus-has-spread/]

3. Lauer SA, Grantz KH, Bi Q, Jones FK, Zheng Q, Meredith HR, et al. The incubation period of coronavirus disease 2019 (COVID-19) from publicly reported confirmed cases: estimation and application. Ann Intern Med. 2020; 172: 577-82.

4. World Health Organization. Estimating mortality from COVID-19. Scientific Brief. [Updated on 4th August 2020, accessed on 26 October 2020]. [Available at: https://www.who.int/news-room/commentaries/ detail/estimating-mortality-from-covid-19]

5. Huang C, Wang Y, Li X, Ren L, Zhao J, Hu Y, et al. Clinical features of patients infected with 2019 novel coronavirus in Wuhan, China. Lancet. 2020; 395: 497-506.

6. Yang X, Yu Y, Xu J, Shu H, Liu H, Wu Y, et al. Clinical course and outcomes of critically ill patients with SARS-CoV-2 pneumonia in Wuhan, China: a single-centered, retrospective, observational study. Lancet Respir Med. 2020; 8: 475-81.

7. Rajgor DD, Lee $M H$, Archuleta $S$. The many estimates of the COVID-19 case fatality rate. Lancet Infect Dis. 2020; 20: 7767.

8. Wiersinga WJ, Rhodes A, Cheng AC. Pathophysiology, transmission, diagnosis, and treatment of coronavirus disease 2019 (COVID-19): a review. JAMA. 2020; 324: 78293.

9. Zhou M, Zhang X, Qu J. Coronavirus disease 2019 (COVID- 
19): a clinical update. Front Med. 2020; 14: 126-35.

10. International Severe Acute Respiratory and emerging Infection Consortium (ISARIC). COVID-19 Clinical Research Resources. Case Report form. [Available at: https://media.tghn.org/medialibrary/2020/03/ISARIC_CO VID-19_CRF_V1.3_24Feb2020.pdf]

11. World Health Organization. Imterim Guidance: Clinical Management of severe acute respiratory when covid-19 disease is suspected. March 2020. Geneva. [Available at: https://apps.who.int/iris/bitstream/handle/10665/33144 6/WHO-2019-nCoV-clinical-2020.4-chi.pdf]

12. Force $A D$, Ranieri VM, Rubenfeld GD, Thompson BT, Ferguson ND, Caldwell E, et al. Acute respiratory distress syndrome. JAMA. 2012; 307: 2526-33.

13. Centers for disease control and prevention (CDC). Overweight and Obesity. Defining adult overweight and obesity. [Accessed online: 2 March 2021]. [Available online: https://www.cdc.gov/obesity/adult/defining.html]

14. Li LQ, Huang $T$, Wang YQ, Wang ZP, Liang $Y$, Huang TB, et al. COVID-19 patients' clinical characteristics, discharge rate, and fatality rate of meta-analysis. J Med Virol. 2020 ; 92: 577-83.

15. Zhang J, Wang X, Jia X, Li J, Hu K, Chen G, et al. Risk factors for disease severity, unimprovement, and mortality of COVID19 patients in Wuhan, China. Clin. Microbiol Infect. 2020; 26: 767-72.

16. Wang $R$, Pan $M$, Zhang $X$, Han $M$, Fan X, Zhao F, et al. Epidemiological and clinical features of 125 Hospitalized Patients with COVID-19 in Fuyang, Anhui, China. Int J Infect Dis. 2020; 95: 421-8.

17. $X u X W, W u X X$, Jiang $X G, X u K J$, Ying $L J, M a C L$, et al. Clinical findings in a group of patients infected with the 2019 novel coronavirus (SARS-Cov-2) outside of Wuhan, China: retrospective case series. BMJ. 2020; 368: $\mathrm{m} 606$

18. Sun Y, Koh V, Marimuthu K, Ng OT, Young B, Vasoo S, et al. Epidemiological and clinical predictors of COVID-19. Clin. Infect. Dis. 2020; 71:786-92.

19. Guan WJ, Ni ZY, Hu Y, Liang WH, Ou CQ, He JX, et al. Clinical characteristics of coronavirus disease 2019 in China. NEJM. 2020; 382: 1708-20.

20. Pan L, Mu M, Yang $P$, Sun $Y$, Wang R, Yan J, et al. Clinical characteristics of COVID-19 patients with digestive symptoms in Hubei, China: a descriptive, cross-sectional, multicenter study. Am J Gastroenterol. 2020; 115: 766-73.

21. Rothan HA, Byrareddy SN. The epidemiology and pathogenesis of coronavirus disease (COVID-19) outbreak. J Autoimmun. 2020; 109: 102433.

22. Lian J, Jin X, Hao S, Cai H, Zhang S, Zheng L, et al. Analysis of epidemiological and clinical features in older patients with coronavirus disease 2019 (COVID-19) outside Wuhan. Clin Infect Dis. 2020; 71: 740-7.

23. Zhou F, Yu T, Du R, Fan G, Liu Y, Liu Z, et al. Clinical course and risk factors for mortality of adult inpatients with COVID-19 in Wuhan, China: a retrospective cohort study. Lancet. 2020; 395; 1054-62.

24. Yang J, Zheng Y, Gou X, Pu K, Chen Z, Guo Q, et al. Prevalence of comorbidities and its effects in patients infected with SARS-CoV-2: a systematic review and meta-analysis. Int J Infect Dis. 2020; 94: 91-5.

25. Emami A, Javanmardi F, Pirbonyeh N. Prevalence of underlying diseases in hospitalized patients with COVID-19: a systematic review and meta-analysis. Arch Acad. Emerg. 2020; 8: e35-40. 